\title{
Intermediate-term trends in serum levels of metal ions after hip resurfacing arthroplasty
}

Wenxue Jiang ${ }^{1 *}$, Yanlin Wan ${ }^{1}$, Peng Cui ${ }^{2}$ and Xianjia Ning ${ }^{3}$

\begin{abstract}
Background: The potential risks associated with hip resurfacing arthroplasty (HRA) are controversial and underestimated. The aim of this study was to explore intermediate-term trends for the levels of cobalt (Co), chromium (Cr), and molybdenum (Mo) ions after HRA.

Methods: Forty patients who underwent HRA from October 2005 to December 2010 were recruited to this study. The serum levels of metal ions were examined preoperatively and 3,12, 24, and 60 months after surgery. Trends and differences in levels of metal ions with respect to sex, operated side, and body mass index (BMI) were analyzed.

Results: There were no significant differences in levels of $\mathrm{Cr}, \mathrm{Co}$, and $\mathrm{Mo}$ at each time point with respect to sex, operated side, and BMI ( $p>0.05)$. The postoperative levels of $\mathrm{Cr}$, Co, and Mo ions were significantly higher than the preoperative levels across sex, operated side, and BMI groups. Postoperative levels of $\mathrm{Cr}, \mathrm{Co}$, and Mo peaked at 12, 24, and 60 months, respectively. Cr levels peaked earlier (at 12 months) in the overweight (BMl $\geq 25 \mathrm{~kg} / \mathrm{m}^{2}$ ) group compared to the normal-weight group (BMl $<25 \mathrm{~kg} / \mathrm{m}^{2}$ ), Co levels (at 12 months) peaked in women compared to men, and Mo levels (at 3 months) peaked in the bilateral HRA group compared to the unilateral HRA group.
\end{abstract}

Conclusions: Serum levels of $\mathrm{Cr}, \mathrm{Co}$, and Mo increased significantly after HRA. Cr levels peaked earlier in the overweight patients, Co levels peaked in women, and Mo levels peaked in patients who underwent bilateral HRA. However, there were no significant differences with respect to sex, operated side, and BMI.

Keywords: Hip resurfacing arthroplasty, Metal ion, Secular trends, Follow-up, Inductively coupled plasma mass spectrometry

\section{Introduction}

Hip resurfacing arthroplasty (HRA) has recently been extensively used in young, active patients with osteoarthritis or other degenerative diseases of the hip joint [1-5]. However, the metal-on-metal prosthesis gradually releases cobalt (Co), chromium (Cr), and molybdenum (Mo) ions. The metal ions may disseminate into the surrounding soft tissues and even into the body [6]. Currently, the factors influencing the serum levels of metal ions remain unclear.

Several adverse effects of metal ions have been reported, including local soft tissue reactions, pseudotumor formation, systemic effects, and elevated deposits of metal ions in target organs [7-11]. Studies performed in European and American countries showed that the location of the prosthesis is associated with the wear rate of the hip joint

\footnotetext{
* Correspondence: jiangwenxue@medmail.com.cn

${ }^{1}$ Department of Orthopedics, Tianjin The First Center Hospital, 24 Fukang Rd., Nankai District, Tianjin 300192, China

Full list of author information is available at the end of the article
}

simulator [12]. However, the relationships between the levels of metal ions released following HRA and patient sex, operated side, and body mass index (BMI) remain unknown.

The purpose of the study was to assess the 5-year trends in the levels of metal ions released and to analyze the relationships between the levels of metal ions and patient sex, operated side, and BMI after HRA. This is the first report of 5-year changes in $\mathrm{Cr}, \mathrm{Co}$, and $\mathrm{Mo}$ levels in patients who had undergone HRA in China.

\section{Patients and methods \\ Patient selection}

The ethics committee of Tianjin First Central Hospital approved the study, and written informed consent was obtained from all participants during recruitment.

From October 2005 to December 2010, 40 patients who were diagnosed with osteoarthritis and inflammatory 
degenerative diseases of the hip joint underwent HRA performed by Wenxue Jiang in the Department of Orthopedics, Tianjin First Central Hospital, China. The diagnosis of osteoarthritis was established based on the patient's symptoms and plain radiography performance; similarly, the diagnosis of inflammatory degenerative diseases was also based on the patient's symptoms and plain radiography performance.

The inclusion criteria of the study were (1) patients with osteonecrosis of the femoral head with Association of Research Circulation Osseous (ARCO) grade IB (defined as the range of necrosis between 15 and $30 \%$ on MRI), IC (defined as a range of necrosis of $\geq 30 \%$ on magnetic resonance imaging (MRI)), IIC (defined as a range of necrosis of $\geq 30 \%$ and the presence of a cystic lesion on MRI), and grade IV (defined as flattening of the femoral head, narrowing of the joint space, and sclerosis of the acetabulum on plain radiography; (2) patients with developmental dysplasia of the hip (DDH) with Crowe grade I (defined as dislocation of the femoral head of $<50 \%$ ), Crowe grade II (defined as displacement of the proximal femur between 0.1 and $0.15 \%$ of pelvic height), or Crowe grade III (defined as the displacement of proximal femur between 0.15 and $0.20 \%$ of pelvis height or dislocation of femoral head between 75 and $100 \%$ ); (3) young, active patients between 20 and 64 years of age; (4) patients with severe hip joint pain that strongly affected the patient's daily activities; (5) failed trials of nonoperative treatments; (6) patients with favorable bone mass based on the proximal femur; (7) patients with no deformities in the proximal femur; and (8) patients with normal liver and renal function [13].

The exclusion criteria were (1) severe proximal femur osteoporosis based on the Singh index (defined as Singh index 24) [14], (2) grade IV dysplasia based on the Crowe classification [15], (3) known allergy to metal, (4) bone tumors, (5) liver or renal dysfunction, and (6) patients with diabetes, gout, or other diseases. All assessments were performed by $\mathrm{PC}$, who did not attend the treatments.

\section{Surgical procedure}

The operation was performed with the patient in the lateral decubitus position with the operated side facing up, as recommended by McMinn et al. [16]. After acetabular preparation, the acetabular component was impacted until fully seated, with a position of $40^{\circ}$ abduction and $20^{\circ}$ anteversion. Pressure was applied to stabilize the acetabular prosthesis. On the femoral head side, any cystic lesion was resected radically. The femoral prosthesis was inserted and fixed with bone cement. The femoral neck was supported with a band to avoid forming a notch at the junction of the femoral head and neck (Figs. 1 and 2).

\section{Measurement of metal ion levels in serum}

Whole-blood samples were collected preoperatively and at $3,12,24$, and 60 months postoperatively to assess the levels of $\mathrm{Co}, \mathrm{Cr}$, and Mo ions. The fasting blood sample was collected in a 10-ml plastic vacuum serum separator blood collection tube. The first $10 \mathrm{ml}$ of blood was discarded to prevent metal contamination from the needle. The second $10 \mathrm{ml}$ of blood was centrifuged at $4000 \mathrm{rpm}$ for $5 \mathrm{~min}$ after incubating $30 \mathrm{~min}$. The serum was drawn into a plastic tube with a sealed cap using a plastic suction device and was then stored at $-20{ }^{\circ} \mathrm{C}$. Subsequently, $0.5 \mathrm{ml}$ of nitric acid was added to $0.5 \mathrm{ml}$ of serum, and the mixture was incubated for $24 \mathrm{~h} ; 4 \mathrm{ml}$ of deionized distilled water was then added into the mixture and the volume was measured. After centrifuging at $8000 \mathrm{rpm}$ for $3 \mathrm{~min}$, the supernatant was removed and was used to measure the levels of $\mathrm{Co}, \mathrm{Cr}$, and Mo ions in triplicate. The serum levels of $\mathrm{Co}, \mathrm{Cr}$, and Mo ions were determined using an inductively coupled plasma mass spectrometer at the Experimental Center of Nankai University, China. We also assessed the preoperative renal function of all patients by measuring the serum urea and creatinine levels.

\section{Statistical analysis}

Metal ion levels were expressed as the median and range, due to the asymmetrical distribution of the metal ion levels. Differences in the levels of metal ions between men and women, patients who had undergone unilateral and bilateral HRA, and those with body mass indexes (BMI) $<25 \mathrm{~kg} / \mathrm{m}^{2}$ and BMI $\geq 25 \mathrm{~kg} / \mathrm{m}^{2}$ were analyzed using a nonparametric Mann-Whitney $U$ test. Changes in time trends of metal ion levels were analyzed using the Kruskal-Wallis test. Age was represented as mean \pm standard deviation. Statistical significance was set at $p<0.05$. All statistical analyses were performed using SPSS software (version 15.0; SPSS Inc. Chicago, IL).

\section{Results \\ Clinical characteristics of patients}

In all, 40 patients were included in this study, including 19 (47.5\%) men and 21 (52.5\%) women. The mean age at surgery was 49.2 years overall (range, 26-64 years), 46.2 years in men (range, $26-58$ years), and 52.0 years in women (range, 26-64 years), $p=0.062$. The mean follow-up time was 24.1 months (range, 3-76 months). All patients underwent HRA with a metal-on-metal prosthesis. Twenty-eight patients $(70 \%)$ underwent bilateral resurfacing, and $12(30 \%)$ patients underwent unilateral resurfacing; there were no significant differences in the operated side between men and women (Table 1). The levels of serum urea and creatinine did not change during the study period. 

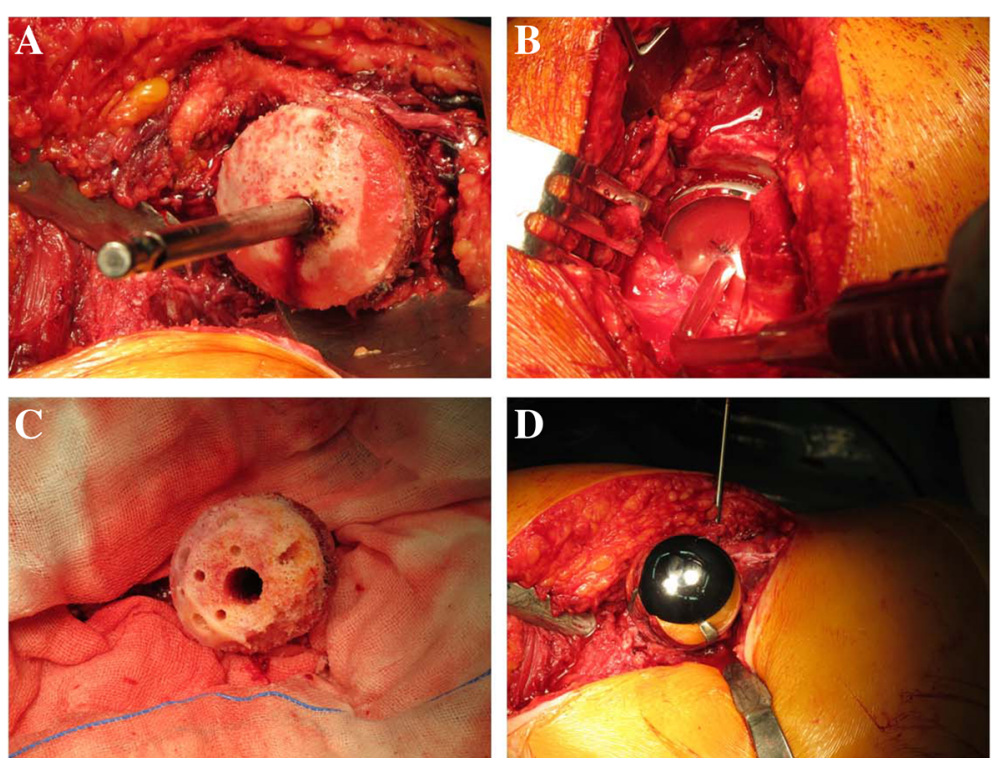

Fig. 1 The process of surgical operation. a To perform borehole and bearizing on the center of the femur head under the conducting by a director. $\mathbf{b}$ To resect the acetabular labrum and burr until bleeding on the cartilage articularis, to impact the appropriate acetabular prosthesis with a position of $40^{\circ}$ abduction and $20^{\circ}$ anteversion, and to pressure for stabilization. c To burr the femur head using the barrel file and to resect the cystic lesion. $\mathbf{d}$ To embed the femoral prosthesis and fix with bone cement. Intraoperative photograph showing the embedded femoral prosthesis fixed with bone cement

\section{Metal ion levels over time by sex, laterality, and BMI}

As shown in Table 2, the levels of $\mathrm{Cr}$, Co, and Mo at each time point were not significantly different when sex, operated side, and BMI groups were considered $(p>0.05)$. However, $\mathrm{Cr}$ levels were higher in women than in men $(1.20 \mathrm{ng} / \mathrm{ml}$ vs. $1.88 \mathrm{ng} / \mathrm{ml} ; p=0.040)$ at 24 months postoperatively and in the BMI $<25 \mathrm{~kg} / \mathrm{m}^{2}$ group than in the BMI $\geq 25 \mathrm{~kg} / \mathrm{m}^{2}$ group preoperatively $(0.73 \mathrm{ng} / \mathrm{ml}$ vs. $0.66 \mathrm{ng} / \mathrm{ml} ; p=0.037)$.

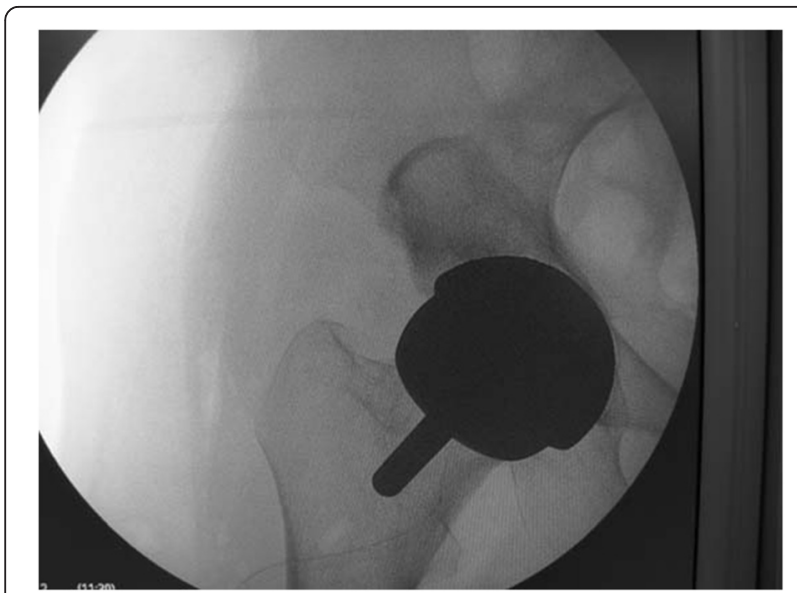

Fig. 2 The X-ray plain film of prosthesis location. The X-ray plain film shows that the location of prosthesis is good during the operation. Postoperative radiograph showing typical hip resurfacing arthroplasty in the anteroposterior view
Table 1 Demographic and clinical characteristics of patients

\begin{tabular}{lllll}
\hline Characteristic & Men & Women & Total & $p$ \\
\hline Number, $n$ (\%) & 19 & 21 & 40 & - \\
Age, year, mean (SD) & $46.2(9.5)$ & $52.0(9.6)$ & $49.2(9.8)$ & 0.062 \\
BMI, kg/m ${ }^{2}$, mean (SD) & $25.3(3.7)$ & $24.4(2.6)$ & $24.9(3.2)$ & 0.409 \\
Diagnosis, $n$ (\%) & & & & 0.085 \\
ONFH & $9(47.4)$ & $6(28.6)$ & $15(37.5)$ & \\
OA & $2(10.5)$ & 0 & $2(5)$ & \\
DDH & $4(21.1)$ & $10(47.6)$ & $14(35)$ & \\
RA & $1(5.3)$ & $3(14.3)$ & $4(10)$ & \\
AS & $3(15.8)$ & 0 & $3(7.5)$ & \\
Others & 0 & $2(9.5)$ & $2(4.0)$ & \\
Operated side, $n$ (\%) & & & & 0.836 \\
Unilateral & $13(68.4)$ & $15(71.4)$ & $28(70)$ & \\
Bilateral & $6(31.6)$ & $6(28.6)$ & $12(30)$ & \\
Prosthesis company, $n(\%)$ & & & & 0.464 \\
Conserve Plus & $12(63.2)$ & $10(47.6)$ & $22(55)$ & \\
BHR & $2(10.5)$ & $6(28.6)$ & $8(20)$ & \\
BMHR & $3(15.8)$ & $4(19)$ & $7(17.5)$ & \\
Depuy ASR-TM & $2(10.5)$ & $1(4.8)$ & $3(7.5)$ & \\
\hline
\end{tabular}

$S D$ standard deviation, $B M I$ body mass index, ONFH osteonecrosis of the femoral head, $O A$ osteoarthritis, $D D H$ developmental dysplasia of the hip, $R A$ rheumatoid arthritis, $A S$ ankylosing spondylitis 
Table 2 Levels of metal ions over time by sex, side, and body mass index

\begin{tabular}{|c|c|c|c|c|c|c|}
\hline Time point & $\mathrm{Cr}$ & $p$ & Co & $p$ & Mo & $p$ \\
\hline \multicolumn{7}{|l|}{ Preoperation } \\
\hline Men & $0.70(0.03)$ & 0.949 & $0.72(0.04)$ & 0.949 & $0.82(0.02)$ & 0.564 \\
\hline Women & $0.70(0.03)$ & & $0.74(0.03)$ & & $0.83(0.02)$ & \\
\hline Unilateral & $0.68(0.03)$ & 0.478 & $0.72(0.04)$ & 0.848 & $0.82(0.02)$ & 0.564 \\
\hline Bilateral & $0.72(0.02)$ & & $0.74(0.03)$ & & $0.83(0.02)$ & \\
\hline $\mathrm{BMI}<25 \mathrm{~kg} / \mathrm{m}^{2}$ & $0.73(0.02)$ & 0.037 & $0.71(0.02)$ & 0.196 & $0.83(0.01)$ & 0.518 \\
\hline $\mathrm{BMI} \geq 25 \mathrm{~kg} / \mathrm{m}^{2}$ & $0.66(0.02)$ & & $0.76(0.04)$ & & $0.81(0.02)$ & \\
\hline \multicolumn{7}{|l|}{3 months } \\
\hline Men & $1.06(0.16)$ & 0.668 & $1.55(0.56)$ & 0.116 & $6.26(1.41)$ & 0.253 \\
\hline Women & $1.30(0.29)$ & & $2.01(0.57)$ & & $7.23(0.88)$ & \\
\hline Unilateral & $1.15(0.21)$ & 0.237 & $1.97(0.50)$ & 0.866 & $6.16(0.78)$ & 0.176 \\
\hline Bilateral & $1.31(0.22)$ & & $1.21(0.15)$ & & $8.86(2.01)$ & \\
\hline $\mathrm{BMI}<25 \mathrm{~kg} / \mathrm{m}^{2}$ & $1.16(0.22)$ & 0.253 & $2.97(1.05)$ & 0.288 & $4.68(0.56)$ & 0.235 \\
\hline $\mathrm{BMI} \geq 25 \mathrm{~kg} / \mathrm{m}^{2}$ & $1.20(0.22)$ & & $1.44(0.36)$ & & $7.41(0.92)$ & \\
\hline \multicolumn{7}{|l|}{12 months } \\
\hline Men & $1.80(0.52)$ & 0.487 & $2.16(0.59)$ & 0.298 & $6.91(1.06)$ & 0.817 \\
\hline Women & $1.81(0.4)$ & & $3.19(0.72)$ & & $7.10(0.78)$ & \\
\hline Unilateral & $1.67(0.37)$ & 0.713 & $2.32(0.55)$ & 0.327 & $7.35(0.66)$ & 0.540 \\
\hline Bilateral & $2.06(0.62)$ & & $3.50(0.88)$ & & 6.33 (1.39) & \\
\hline $\mathrm{BMI}<25 \mathrm{~kg} / \mathrm{m}^{2}$ & $3.03(1.47)$ & 0.243 & $3.41(1.86)$ & 0.322 & $6.86(3.65)$ & 0.493 \\
\hline $\mathrm{BM} \mathrm{I} \geq 25 \mathrm{~kg} / \mathrm{m}^{2}$ & $1.61(0.28)$ & & $2.60(0.50)$ & & $7.03(0.6)$ & \\
\hline \multicolumn{7}{|l|}{24 months } \\
\hline Men & $1.20(0.39)$ & 0.04 & $2.96(0.78)$ & 0.661 & $4.67(0.42)$ & 0.242 \\
\hline Women & $1.88(0.30)$ & & $3.09(0.59)$ & & $5.55(0.86)$ & \\
\hline Unilateral & $1.53(0.27)$ & 0.236 & $3.00(0.46)$ & 0.693 & $4.84(0.48)$ & 0.324 \\
\hline Bilateral & $2.08(0.75)$ & & $3.26(2.04)$ & & $7.23(2.56)$ & \\
\hline $\mathrm{BMI}<25 \mathrm{~kg} / \mathrm{m}^{2}$ & $1.85(0.45)$ & 0.938 & $3.40(0.74)$ & 0.721 & $4.35(0.74)$ & 0.276 \\
\hline $\mathrm{BMI} \geq 25 \mathrm{~kg} / \mathrm{m}^{2}$ & $1.47(0.3)$ & & $2.81(0.60)$ & & $5.75(0.74)$ & \\
\hline \multicolumn{7}{|l|}{60 months } \\
\hline Men & $1.17(0.11)$ & 0.584 & $3.60(0.62)$ & 0.361 & $7.42(0.57)$ & 0.584 \\
\hline Women & $1.24(0.28)$ & & $2.52(0.720$ & & $7.60(1.32)$ & \\
\hline Unilateral & $1.33(0.28)$ & 0.855 & $2.54(0.70)$ & 0.465 & $7.04(1.25)$ & 0.361 \\
\hline Bilateral & $1.06(0.06)$ & & $3.63(0.66)$ & & $8.09(0.67)$ & \\
\hline $\mathrm{BMI}<25 \mathrm{~kg} / \mathrm{m}^{2}$ & $1.29(0.24)$ & 1.000 & $2.80(0.63)$ & 0.850 & $7.12(1.1)$ & 0.345 \\
\hline $\mathrm{BMI} \geq 25 \mathrm{~kg} / \mathrm{m}^{2}$ & $1.06(0.08)$ & & $3.45(0.87)$ & & $8.22(0.65)$ & \\
\hline
\end{tabular}

Data shown as mean (standard error)

Trends for metal ion levels during the 5-year follow-up Overall, the postoperative serum levels of $\mathrm{Cr}$, $\mathrm{Co}$, and Mo were significantly higher than the preoperative levels across sex, operated side, and BMI groups. Postoperative serum Cr levels peaked at 12 months, Co levels peaked at 24 months, and Mo levels peaked at 60 months. The respective ion levels peaked at 12,60 , and 60 months for men and 24, 12, and 60 months in women; 12, 24, and 12 months in the unilaterally operated group and 24, 60, and 3 months for the bilaterally operated group; and 24, 24 , and 60 months for the BMI $<25 \mathrm{~kg} / \mathrm{m}^{2}$ group and 12,60 , and 60 months for the BMI $\geq 25 \mathrm{~kg} / \mathrm{m}^{2}$ group (all $p<0.05)$. The trends for $\mathrm{Cr}$, Co, and Mo levels before and after HRA are summarized in Table 3.

\section{Complications and survival rate of prostheses after HRA} Only one patient experienced femoral neck fracture after HRA among all 40 patients during follow-up, which was 
Table 3 Levels of metal ions over time by sex, laterality, and body mass index

\begin{tabular}{|c|c|c|c|c|c|}
\hline Category & Preoperation & 3 months & 12 months & 24 months & 60 months \\
\hline \multicolumn{6}{|l|}{ Total } \\
\hline $\mathrm{Cr}, \mathrm{ng} / \mathrm{ml}$ & $0.70(0.02)$ & $1.19(0.17)^{*}$ & $1.80(0.31)^{*}$ & $1.62(0.25)^{*}$ & $1.20(0.15)^{*}$ \\
\hline $\mathrm{Co}, \mathrm{ng} / \mathrm{ml}$ & $0.73(0.02)$ & $1.79(0.39)^{*}$ & $2.71(0.48)^{*}$ & $3.04(0.45)^{*}$ & $3.04(0.49)^{*}$ \\
\hline Mo, ng/ml & $0.82(0.01)$ & $6.78(0.78)^{*}$ & $7.01(0.62)^{*}$ & $5.21(0.55)^{*}$ & $7.52(0.73)^{*}$ \\
\hline \multicolumn{6}{|l|}{ Men } \\
\hline $\mathrm{Cr}, \mathrm{ng} / \mathrm{ml}$ & $0.70(0.03)$ & $1.06(0.16)$ & $1.8(0.52)^{*}$ & $1.2(0.39)^{*}$ & $1.17(0.11)^{*}$ \\
\hline $\mathrm{Co}, \mathrm{ng} / \mathrm{ml}$ & $0.72(0.04)$ & $1.55(0.56)^{*}$ & $2.16(0.59)^{*}$ & $2.96(0.78)^{*}$ & $3.6(0.62)^{*}$ \\
\hline Mo, g/ml & $0.82(0.02)$ & $6.26(1.41)^{*}$ & $6.91(1.06)^{*}$ & $4.67(0.42)^{*}$ & $7.42(0.57)^{*}$ \\
\hline \multicolumn{6}{|l|}{ Women } \\
\hline $\mathrm{Cr}, \mathrm{ng} / \mathrm{ml}$ & $0.70(0.03)$ & $1.30(0.29)^{*}$ & $1.81(0.40)^{*}$ & $1.88(0.30)^{*}$ & $1.24(0.28)^{*}$ \\
\hline Co, ng/ml & $0.74(0.03)$ & $2.01(0.57)^{*}$ & $3.19(0.72)^{*}$ & $3.09(0.59)^{*}$ & $2.52(0.72)^{*}$ \\
\hline Mo, g/ml & $0.83(0.02)$ & $7.23(0.88)^{*}$ & $7.1(0.78)^{*}$ & $5.55(0.86)^{*}$ & $7.6(1.32)^{*}$ \\
\hline \multicolumn{6}{|l|}{ Unilateral } \\
\hline $\mathrm{Cr}, \mathrm{ng} / \mathrm{ml}$ & $0.68(0.03)$ & $1.15(0.21)^{*}$ & $1.67(0.37)^{*}$ & $1.53(0.27)^{*}$ & $1.33(0.28)^{*}$ \\
\hline $\mathrm{Co}, \mathrm{ng} / \mathrm{ml}$ & $0.72(0.04)$ & $1.97(0.5)^{*}$ & $2.32(0.55)^{*}$ & $3.00(0.46)^{*}$ & $2.54(0.7)^{*}$ \\
\hline Mo, g/ml & $0.82(0.02)$ & $6.16(0.78)^{*}$ & $7.35(0.66)^{*}$ & $4.84(0.48)^{*}$ & $7.04(1.25)^{*}$ \\
\hline \multicolumn{6}{|l|}{ Bilateral } \\
\hline $\mathrm{Cr}, \mathrm{ng} / \mathrm{ml}$ & $0.72(0.02)$ & $1.31(0.22)$ & $2.06(0.62)^{*}$ & $2.08(0.75)^{*}$ & $1.06(0.06)^{*}$ \\
\hline $\mathrm{Co}, \mathrm{ng} / \mathrm{ml}$ & $0.74(0.03)$ & $1.21(0.15)$ & $3.50(0.88)^{*}$ & $3.26(2.04)$ & $3.63(0.66)^{*}$ \\
\hline Mo, g/ml & $0.83(0.020$ & $8.86(2.01)^{*}$ & $6.33(1.39)^{*}$ & $7.23(2.56)$ & $8.09(0.67)^{*}$ \\
\hline \multicolumn{6}{|c|}{$\mathrm{BMI}<25 \mathrm{~kg} / \mathrm{m}^{2}$} \\
\hline $\mathrm{Cr}, \mathrm{ng} / \mathrm{ml}$ & $0.73(0.02)$ & $1.16(0.22)$ & $3.03(1.47)$ & $1.85(0.45)^{*}$ & $1.29(0.24)^{*}$ \\
\hline $\mathrm{Co}, \mathrm{ng} / \mathrm{ml}$ & $0.71(0.02)$ & $2.97(1.05)^{*}$ & $3.41(1.86)$ & $3.40(0.74)^{*}$ & $2.8(0.63)^{*}$ \\
\hline Mo, g/ml & $0.83(0.01)$ & $4.68(0.56)^{*}$ & $6.86(3.65)$ & $4.35(0.74)^{*}$ & $7.12(1.1)^{*}$ \\
\hline \multicolumn{6}{|c|}{$\mathrm{BMI} \geq 25 \mathrm{~kg} / \mathrm{m}^{2}$} \\
\hline $\mathrm{Cr}, \mathrm{ng} / \mathrm{ml}$ & $0.66(0.02)$ & $1.20(0.22)^{*}$ & $1.61(0.28)^{*}$ & $1.47(0.3)^{*}$ & $1.06(0.08)^{*}$ \\
\hline $\mathrm{Co}, \mathrm{ng} / \mathrm{ml}$ & $0.76(0.04)$ & $1.44(0.36)^{*}$ & $2.60(0.5)^{*}$ & $2.81(0.6)^{*}$ & $3.45(0.87)^{*}$ \\
\hline Mo, $\mathrm{g} / \mathrm{ml}$ & $0.81(0.02)$ & $7.41(0.92)^{*}$ & $7.03(0.6)^{*}$ & $5.75(0.74)^{*}$ & $8.22(0.65)^{*}$ \\
\hline
\end{tabular}

Data shown as mean (standard error)

* Indicated $p<0.05$ by nonparametric Kruskal-Wallis test. Data shown as mean (standard error)

pathologically diagnosed as osteonecrosis of the femoral head [10]. Except for this patient, no cases presented any complication, including an anaphylactic reaction to the metal ions, continuous pain in the groin, red/swollen skin and/or pruritus around the prosthesis, or malignancy. No surgery-related deaths occurred during the follow-up period, and the overall survival rate of the prostheses was $97.5 \%$.

\section{Discussion}

In this study, we found that postoperative levels of $\mathrm{Cr}$, $\mathrm{Co}$, and Mo were significantly higher than preoperative levels across sex, operated side, and BMI groups. There were few significant differences in the levels of $\mathrm{Cr}, \mathrm{Co}$, and Mo at each time point by sex, operated side, and $\mathrm{BMI}$ groups, except that $\mathrm{Cr}$ levels were higher in women than in men 24 months postoperatively and in the BMI $<25 \mathrm{~kg} / \mathrm{m}^{2}$ group than in the BMI $\geq 25 \mathrm{~kg} / \mathrm{m}^{2}$ group preoperatively. In addition, $\mathrm{Cr}$ levels peaked earlier in the BMI $\geq 25 \mathrm{~kg} / \mathrm{m}^{2}$ group at 12 months, Co levels peaked in women at 12 months, and Mo levels peaked in the bilateral group at 3 months.

HRA has recently been extensively applied in young patients owing to a survival rate of $99 \%$ and is the better option for young patients than is total hip replacement [17-24]. However, it has been established that the levels of metal ions in circulation in vivo increase persistently following HRA [25-27]. Researchers worldwide have noted this issue, though the long-term clinical effects remain undetermined.

Daniel et al. [28] analyzed the whole-blood levels of $\mathrm{Co}$ and $\mathrm{Cr}$ among 24 patients who had undergone 
unilateral HRA and found that Co and $\mathrm{Cr}$ levels were significantly increased after 1 year, followed by a decreasing trend until the sixth year. Yang et al. [25] assessed the levels of $\mathrm{Co}$ and $\mathrm{Cr}$ in 21 patients who underwent HRA and found a consistent increase in Co and $\mathrm{Cr}$ serum levels; $\mathrm{Co}$ and $\mathrm{Cr}$ levels peaked at 6 months (increased by 7.8-fold for Co and 10.1-fold for $\mathrm{Cr}$ ) and at 9 months (increased by 4.7 -fold for $\mathrm{Co}$, and 7.8-fold for $\mathrm{Cr}$ ), respectively, followed by a gradual decline after 6 months (levels were 3.6-fold for Co and 5.1-fold for $\mathrm{Cr}$ at 24 months). Levine et al. [17] found that the levels of $\mathrm{Co}$ and $\mathrm{Cr}$ ions were elevated in three implant groups (hybrid group, $\mathrm{CoCr}$ group, and titanium group) at all follow-up periods compared with those in the control group, and the mean $\mathrm{Cr}$ levels for the hybrid and $\mathrm{CoCr}$ groups were higher at 120 months compared to baseline levels, with increases of 3.9-fold and 3.6-fold, respectively. In contrast to these previous studies, we found that the postoperative levels of metal ions were elevated; the $\mathrm{Cr}$ level peaked at 12 months (increased by 1.6-fold) postoperatively, the Co level peaked at 60 months (increased by 3.2-fold), and the Mo level peaked at 60 months (increased by 8.2-fold). Compared to the results reported by Daniel et al. [27], our results demonstrated the same peak time for $\mathrm{Cr}$ levels and a delayed peak time for Co levels; however, the peak times of $\mathrm{Cr}$ and Co levels were delayed compared to those in the study reported by Yang et al. [26], in which the levels of $\mathrm{Cr}$ and Co peaked at 6 months postoperatively. The differences in peak time between the previous studies and our study may be explained by differences in prostheses [18], patients (young) [26], and types of operation (unilateral HRA) [28].

Previous studies showed that $\mathrm{Cr}$ levels were higher in women than in men $[17,18,29]$, but we found no differences in levels of Co and Mo between men and women. In line with those studies, we observed an increased level of $\mathrm{Cr}$ in women. However, we did observe an earlier peak time for Co levels in women compared with men. This difference may be explained partly by the physiological differences between men and women.

The relationship of the levels of metal ions and the operated side for HRA is disputed. Moroni et al. [19] advocated that $\mathrm{Cr}$ levels were higher in patients who had undergone bilateral HRA compared with patients who had undergone unilateral HRA, though there was no difference in levels of Co and Mo. deSouza et al. [20] found that the level of Co was significantly increased (by $45 \%)$ in patients who had undergone bilateral HRA. However, a few studies reported no changes in metal ion levels between those who underwent bilateral and unilateral HRA [21-23]. Consistent with the findings in these previous studies, there were no significant differences in metal ion levels between patients who had undergone bilateral and unilateral HRA in the present study. However, there was an earlier peak time for Mo ion level (3 months) in the bilateral HRA group compared to that in the unilateral HRA group. The reason is unknown.

Previous studies have demonstrated no significant relationship between BMI and metal ion levels after HRA $[23,30]$. Consistent with these studies, we found no significant differences in metal ion levels between the normal-weight group and the overweight group postoperatively. However, $\mathrm{Cr}$ peaked earlier in the overweight group than in the normal-weight group. The increased load and wear of the hip joint in patients with a higher BMI after HRA may partly explain the earlier peak for $\mathrm{Cr}$ levels in the overweight group than in the normalweight group [23].

In this study, metal ion levels were measured using inductively coupled plasma mass spectrometry that is associated with high accuracy and less interference and has been extensively applied to measure metal ion levels. There are several limitations in this study. First, there was a small sample size, as only 40 patients were assessed. Second, over the follow-up period of 5 years, measurements were only performed four times. Therefore, further studies with a greater number of postoperative measurements and with larger numbers of patients are necessary to confirm these findings.

\section{Conclusion}

Our study suggests that serum levels of $\mathrm{Cr}, \mathrm{Co}$, and $\mathrm{Mo}$ increase significantly after HRA. Cr levels peaked earlier in the overweight patients, Co levels peaked in women, and Mo levels peaked in patients who underwent bilateral HRA. However, there were no significant differences with respect to sex, operated side, and BMI. A long-term study on the levels of metal ions is necessary to improve understanding of the effects of metal ions after HRA.

\section{Competing interests \\ The authors declare that they have no competing interests.}

\section{Authors' contributions}

WJ made substantial contributions to the conception and design. YW and PC made substantial contributions to the acquisition of data. XN made substantial contributions to the analysis and interpretation of data. WJ and YW were involved in drafting the manuscript and revising it critically for important intellectual content. WJ has given final approval of the version to be published and agrees to be accountable for all aspects of the work in ensuring that questions related to the accuracy or integrity of any part of the work are appropriately investigated and resolved. All authors read and approved the final manuscript.

\section{Acknowledgements}

We thank all participants in this study for their enthusiasm, tireless work, and sustained support.

\section{Author details}

${ }^{1}$ Department of Orthopedics, Tianjin The First Center Hospital, 24 Fukang Rd., Nankai District, Tianjin 300192, China. ${ }^{2}$ Department of Orthopedics, Tianjin Hospital, 406 Jiefang South Road, Hexi District, Tianjin 300210, China. 
${ }^{3}$ Department of Epidemiology, Tianjin Neurological Institute, 154 Anshan Rd, Heping District, Tianjin 300052, China.

Received: 21 July 2015 Accepted: 9 December 2015 Published online: 23 December 2015

\section{References}

1. Hing CB, Back DL, Bailey M, Young DA, Dalziel RE, Shimmin AJ. The results of primary Birmingham hip resurfacings at a mean of five years: an independent prospective review of the first 230 hips. J Bone Joint Surg Br. 2007:89:1431-8

2. Daniel J, Pynsent PB, McMinn DJ. Metal-on-metal resurfacing of the hip in patients under the age of 55 years with osteoarthritis. J Bone Joint Surg Br. 2004;86:177-84

3. Amstutz HC, Le Duff MJ. Eleven years of experience with metal-on-metal hybrid hip resurfacing: a review of 1000 conserve plus. J Arthroplasty. 2008; 23:36-43.

4. Treacy RB, McBryde CW, Shears E, Pynsent PB. Birmingham hip resurfacing: a minimum follow-up of ten years. J Bone Joint Surg Br. 2011;93:27-33.

5. Coulter G, Young DA, Dalziel RE, Shimmin AJ. Birmingham hip resurfacing at a mean of ten years: results from an independent centre. J Bone Joint Surg Br. 2012;94:315-21.

6. Brodner W, Bitzan P, Meisinger V, Kaider A, Gottsauner-Wolf F, Kotz R. Serum cobalt levels after metal-on-metal total hip arthroplasty. J Bone Joint Surg Am. 2003;85:2168-73.

7. Hsu AR, Kim JD, Fabi D, Levine BR. Adverse reactions in metal-onmetal total hip arthroplasty: two cases presenting as pseudoseptic acetabular component loosening. Am J Orthop (Belle Mead NJ). 2011;40:509-13.

8. Watters TS, Eward WC, Hallows RK, Dodd LG, Wellman SS, Bolognesi MP. Pseudotumor with superimposed periprosthetic infection following metal-onmeta total hip arthroplasty: a case report. J Bone Joint Surg Am. 2010;92:1666-9.

9. Tower SS. Arthroprosthetic cobaltism: neurological and cardiac manifestations in two patients with metal-on-metal arthroplasty: a case report. J Bone Joint Surg Am. 2010;92:2847-51.

10. Willert HG, Buchhorn GH, Fayyazi A, Flury R, Windler M, Köster $G$, et al. Metal-on-metal bearings and hypersensitivity in patients with artificial hip joints. A clinical and histomorphological study. J Bone Joint Surg Am. 2005; 87:28-36.

11. Urban RM, Tomlinson MJ, Hall DJ, Jacobs JJ. Accumulation in liver and spleen of metal particles generated at nonbearing surfaces in hip arthroplasty. J Arthroplasty. 2004;19:94-101.

12. Angadji A, Royle M, Collins SN, Shelton JC. Influence of cup orientation on the wear performance of metal-on-metal hip replacements. Proc Inst Mech Eng H. 2009;223:449-57.

13. Zhiyong $\mathrm{H}$, Haishan $\mathrm{W}$. The progress of metal-on-metal total hip resurfacing arthroplasty. J Clin Orthopaedics. 2009;12:90-2.

14. Singh M. Changes in the trabecular pattern of the upper end of the femur as an index of osteoporosis. J Bone Joint Surg Am. 1970;52:457-67.

15. Derek M. Modern hip resurfacing. London: Springer-Verlag Gmbh; 2009. p. 152.

16. McMinn DJ, Daniel J, Ziaee H, Pradhan C. Indications and results of hip resurfacing. Int Orthop. 2011;35:231-7.

17. Levine BR, Hsu AR, Skipor AK, Hallab NJ, Paprosky WG, Galante JO, et al. Ten-year outcome of serum metal ion levels after primary total hip arthroplasty: a concise follow-up of a previous report. J Bone Joint Surg (Am. 2013;95:512-8.

18. Heisel C, Streich N, Krachler M, Jakubowitz E, Kretzer JP. Characterization of the running-in period in total hip resurfacing arthroplasty: an in vivo and in vitro metal ion analysis. J Bone Joint Surg Am. 2008;90:125-33.

19. Moroni A, Savarino L, Hoque M, Cadossi M, Baldini N. Do ion levels in hip resurfacing differ from metal-on-metal THA at midterm? Clin Orthop Relat Res. 2011;469:180-7.

20. de Souza RM, Parsons NR, Oni T, Dalton P, Costa M, Krikler S. Metal ion levels following resurfacing arthroplasty of the hip. J Bone Joint Surg Br. 2010;92:1642-7.

21. Holland JP, Langton DJ, Hashmi M. Ten-year clinical, radiological and metal ion analysis of the Birmingham Hip Resurfacing. J Bone Joint Surg Br. 2012; 94:471-6.
22. Amstutz HC, Takamura KM, Le Duff MJ. The effect of patient selection and surgical technique on the result of Conserve Plus hip resurfacing-3.5 to 14-years follow up. Orhtop clin North Am. 2011;42:133-42.

23. Sawalha S, Ravikumar R, Chowdhury EA, Massraf A. The effect of obesity on blood metal ion levels after hip resurfacing and metal-on-metal total hip replacement. Hip Int. 2012;22:107-12.

24. Vendittoli PA, Mottard S, Roy AG, Dupont C, Lavigne M. Chromium and cobalt ion release following the Durom high carbon content, forged metal-on-metal surface replacement of the hip. J Bone Joint Surg Br. 2007:89:441-8.

25. Yang J, Shen B, Zhou Z, Pei F, Kang P. Changes in cobalt and chromium levels after metal-on-metal hip resurfacing in young, active Chinese patients. J Arthroplasty. 2011;26:65-70.

26. McKellop H, Park SH, Chiesa R, Doorn P, Lu B, Normand P, et al. In vivo wear of three types of metal-on-metal hip prostheses during two decades of use. Clin Orthop Relat Res. 1996;329(Suppl):128-40.

27. Older J. Charnley low-friction arthroplasty: a worldwide retrospective review at 15 to 20 years. J Arthroplasty. 2002;17:675-80.

28. Daniel J, Ziaee H, Pradhan C, McMinn DJ. Six-year results of a prospective study of metal ion levels in young patients with metal-on-metal hip resurfacings. J Bone Joint Surg Br. 2009;91:176-9.

29. Matthies A, Underwood R, Cann P, Ilo K, Nawaz Z, Skinner J, et al. Retrieva analysis of 240 metal-on-metal hip components, comparing modular total hip replacement with hip resurfacing. J Bone Joint Surg Br. 2011;93:307-14.

30. Rahman L, Muirhead-Allwood SK, Alkinj M. What is the midterm survivorship and function after hip resurfacing? Clin Orthop Relat Res. 2010;468:3221-7.

\section{Submit your next manuscript to BioMed Central and we will help you at every step:}

- We accept pre-submission inquiries

- Our selector tool helps you to find the most relevant journal

- We provide round the clock customer support

- Convenient online submission

- Thorough peer review

- Inclusion in PubMed and all major indexing services

- Maximum visibility for your research

Submit your manuscript at www.biomedcentral.com/submit 